

\title{
Operations and Maintenance Philosophy
}

\author{
G. P. Duncan and P. L. Owen
}

Lockheed Martin Hanford Corporation

Richland, WA 99352

U.S. Department of Energy Contract DE-AC06-96RL13200

\author{
EDT/ECN: $627138 \quad$ UC: 721 \\ Org Code: $79 \mathrm{C00} \quad$ Charge Code: 108536 \\ B\&R Code: $\quad$ Total Pages: 41
}

Key Words:

operations, maintenance, philosophy

\begin{abstract}
:
This Operations and Maintenance (O\&M) Philosophy document is intended to establish a future $O \& M$ vision, with an increased focus on minimizing worker exposure, ensuring uninterrupted retrieval operations, and minimizing operation life-cycle cost. It is intended that this document would incorporate O\&M lessons learned into on-going and future project upgrades.
\end{abstract}

TRADEMARK DISCLAIMER. Reference herein to any specific commercial product, process, or service by trade name, trademark, manufacturer, or otherwise, does not necessarily constitute or imply its endorsement, recommendation, or favoring by the United States Government or any agency thereof or its contractors or subcontractors.

Printed in the United States of America. To obtain copies of this document, contact: Document Control Services, P.O. Box 950, Mailstop H6-08, Richland WA 99352, Phone (509) 372-2420; Fax (509) 376-4989.
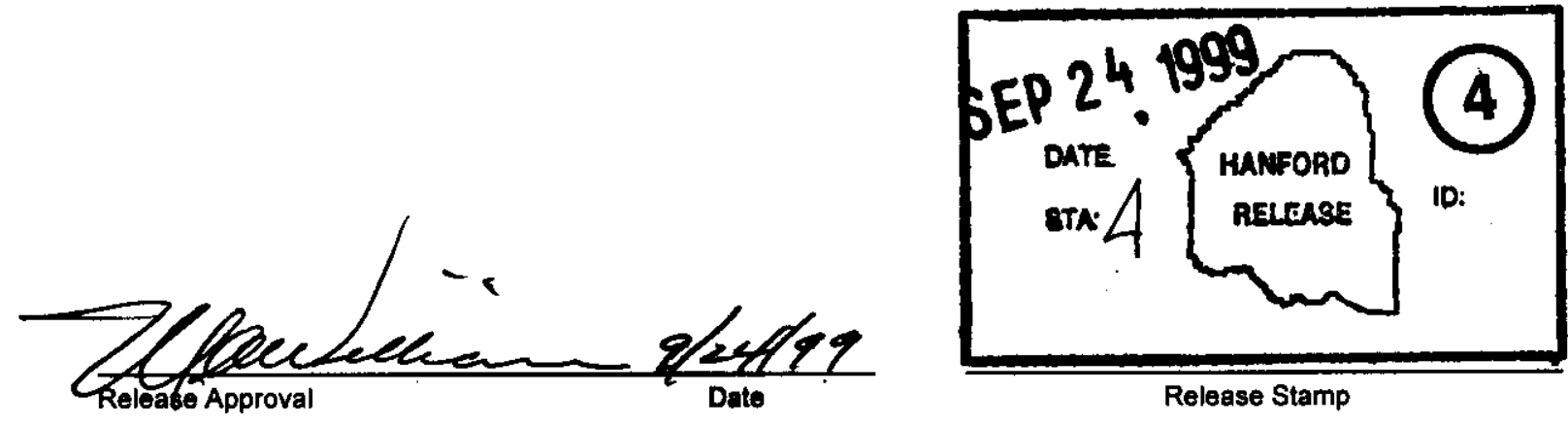

Release Stamp 
HNF-4553

Revision 0

\title{
OPERATIONS AND MAINTENANCE PHILOSOPHY
}

September 1999

\author{
G. P. Duncan \\ Lockheed Martin Hanford Corporation \\ Richland, Washington
}

P. L. Owen

E2 Consulting Engineers

Richland, Washington

Prepared for

U.S. Department of Energy

Richland, Washington 
HNF-4553

Revision 0

This page intentionally left blank. 


\section{CONTENTS}

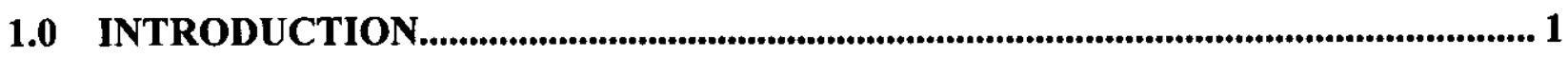

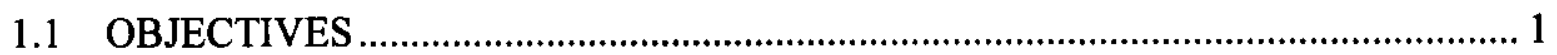

1.2 ASSUMPTIONS (AT THE START OF RETRIEVAL OPERATIONS) .................... 2

1.3 OPERATIONS AND MAINTENANCE ROLES AND RESPONSIBILITIES ........... 2

1.4 STANDARDIZATION OF EQUIPMENT/PROCESSES ……................................... 3

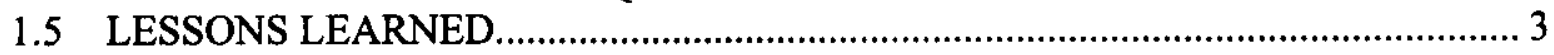

1.6 CONTROL OF POTENTIAL RADIOACTIVE AIRBORNE EMISSIONS................ 3

2.0 MONITORING AND CONTROL SYSTEMS ….............................................................5 5

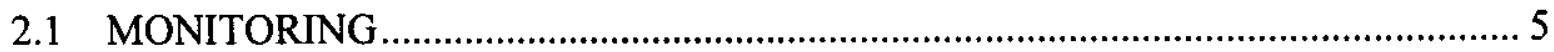

2.1.1 Remote Central Monitoring Station and System .............................................. 6

2.1.2 Local and Local-Remote Monitoring............................................................. 7

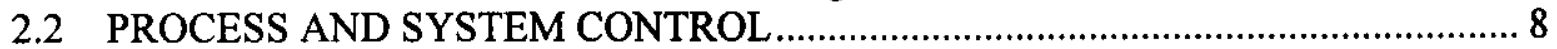

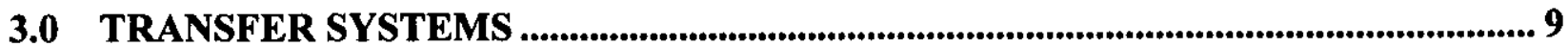

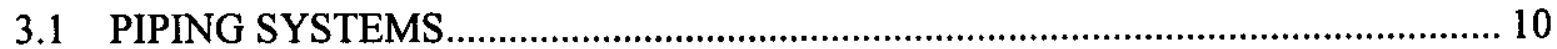

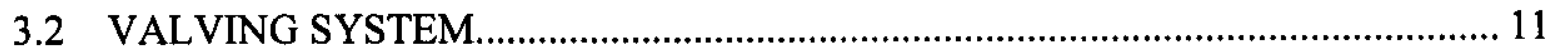

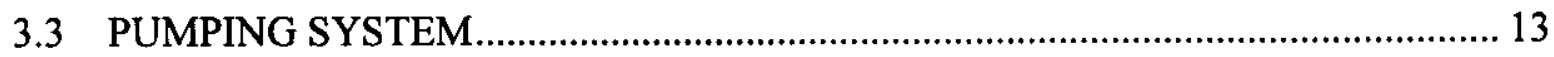

4.0 WASTE PREPARATION SYSTEMS ........................................................................... 15

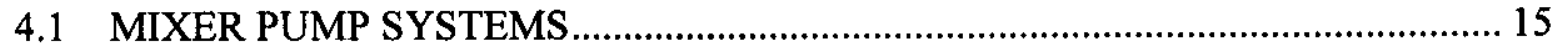

4.2 DILUENT AND FLUSH SYSTEMS

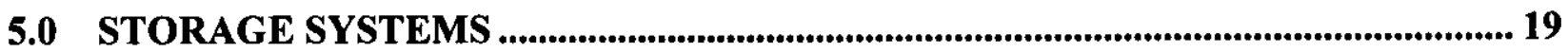

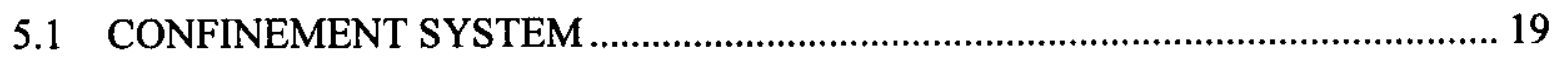

5.2 INSTRUMENTATION AND CONTROL SYSTEMS ............................................ 20

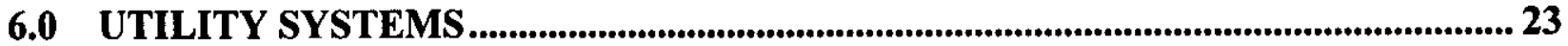

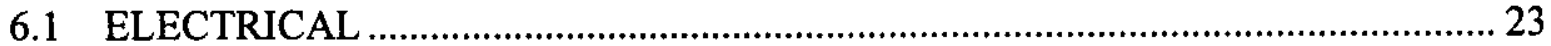

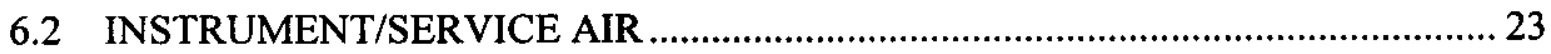

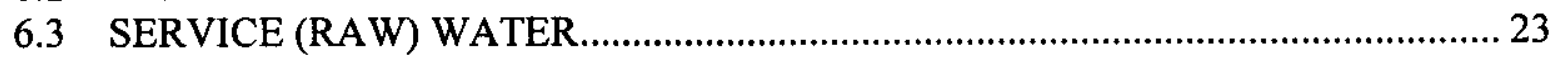

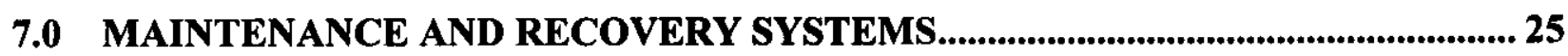

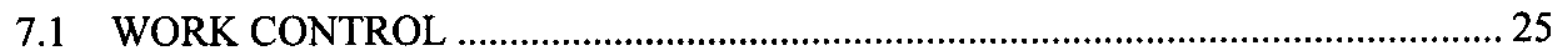

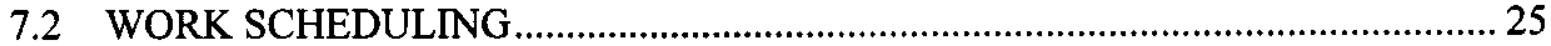

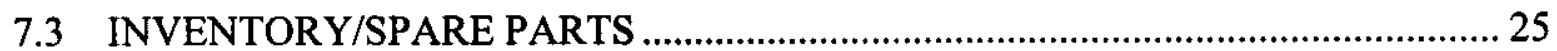

7.4 PIT WORK (VALVE PITS /PUMP PITS/DIVERSION BOXES) ............................ 26

8.0 EQUIPMENT CONFIGURATION CONTROL......................................................... 29

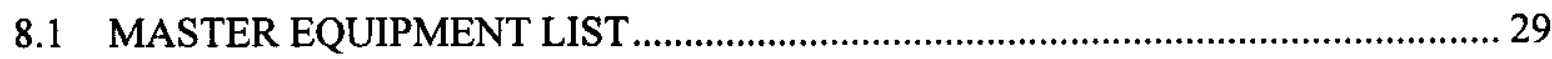

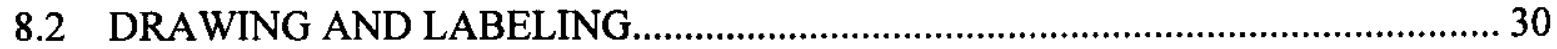

9.0 WASTE SAMPLING SYSTEMS (TBD) ......................................................................... 31

10.0 MISCELLANEOUS SUPPORT SYSTEMS .............................................................. 31 
HNF-4553

Revision 0

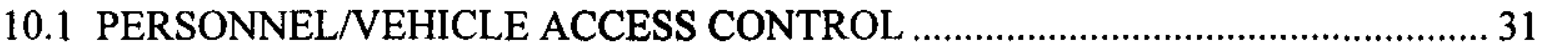

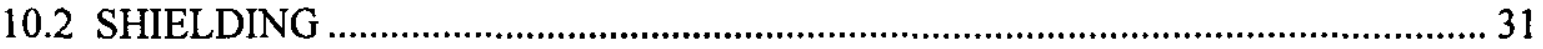

10.3 LIQUID OBSERVATION WELLS IN SINGLE SHELL TANKS ............................ 32

10.4 LONG LENGTH EQUIPMENT LAY-DOWN AREA …………............................ 32

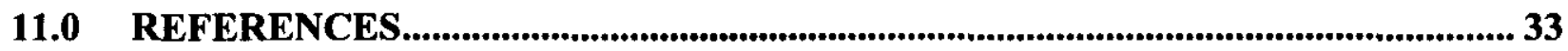

Table 1. Core Operations and Mäntenance Activities.......................................................... 1 
HNF-4553

Revision 0

\section{TERMS AND DEFINITIONS}

Inhibited Flush Water - Process water used for transfer line flushing that contains at least $0.01 \mathrm{M}$ $\mathrm{NaOH}$ and $0.011 \mathrm{M} \mathrm{NaNO}_{2}$

Local - Normally inside the Tank Farm at the physical location of the system.

Local-remote - At a remote station normally located adjacent to the tank farms for which the equipment is being operated (e.g. control rooms and stations).

Remote - A central location from which systems and activities affecting multiple tank farms can be monitored

Shall - Denotes a requirement. Specific equipment requirements should be flowed down through applicable Level Two Equipment Specification documents.

Should - Requires that an objective assessment be performed to determine whether specific factors, criterion, guidelines, standard, etc., will be incorporated into or satisfied by the design. Results of this assessment shall be documented 
HNF-4553

Revision 0

\section{ACRONYMS AND ABBREVIATIONS}

$\begin{array}{ll}\text { AB } & \text { Authorization Basis } \\ \text { AC } & \text { Administrative Control } \\ \text { AGA } & \text { Alternatives Generation and Analysis } \\ \text { ALARACT } & \text { As-Low-As-Reasonably-Achievable Control Technology } \\ \text { CMS } & \text { Central Monitoring Station/System } \\ \text { DST } & \text { Double-shell tank } \\ \text { HLW } & \text { High-level waste } \\ \text { HMI } & \text { Human-Machine Interface } \\ \text { ILAW } & \text { Immobilized low-activity waste } \\ \text { LAW } & \text { Low-activity waste } \\ \text { LOW } & \text { Liquid Observation Well } \\ \text { MBD } & \text { Material Balance Discrepancy } \\ \text { MOV } & \text { Motor-Operated Valve } \\ \text { MPS } & \text { Master Pump Shutdown } \\ \text { O\&M } & \text { Operations and Maintenance } \\ \text { PLC } & \text { Program Logic Controller } \\ \text { PM } & \text { Preventative Maintenance } \\ \text { RPP } & \text { River Protection Project } \\ \text { SEL } & \text { Safety Equipment List } \\ \text { SOM } & \text { Shift Operations Manager } \\ \text { SST } & \text { Single-shell tank } \\ \text { TSR } & \text { Technical Safety Requirement } \\ \text { VPI } & \text { Valve Position Indicator } \\ \text { WFD } & \text { Waste Feed Delivery (Program) }\end{array}$




\section{OPERATIONS AND MAINTENANCE PHILOSOPHY}

\subsection{INTRODUCTION}

\subsection{OBJECTIVES}

This Operations and Maintenance (O\&M) Philosophy document is intended to establish a future O\&M vision, with an increased focus on minimizing worker exposure, ensuring uninterrupted retrieval operations, and minimizing operation life-cycle cost. It is intended that this document would incorporate O\&M lessons learned into on-going and future project upgrades, ensuring an integrated O\&M system is delivered that support the needs of O\&M during the first phase of retrieval operations.

Table 1 shows the O\&M activities considered during the development of this strategy.

Table 1. Core Operations and Maintenance Activities.

\begin{tabular}{|l|l|}
\hline \multicolumn{1}{|c|}{ Core operations } & \multicolumn{1}{c|}{ Activity } \\
\hline Access Control & $\begin{array}{l}\text { Personnel and equipment ingress/egress, dome } \\
\text { loading. }\end{array}$ \\
\hline Emergency Response & $\begin{array}{l}\text { Facility abnormal conditions, site emergency } \\
\text { response }\end{array}$ \\
\hline Facility Configuration Management & $\begin{array}{l}\text { Equipment and facility modifications, drawings } \\
\text { and equipment labeling }\end{array}$ \\
\hline Operational Control & Lock and tag, equipment operations \\
\hline Maintenance & $\begin{array}{l}\text { Facility upgrades, preventive and corrective } \\
\text { maintenance. }\end{array}$ \\
\hline Reporting & $\begin{array}{l}\text { Occurrence reporting, facility status and progress } \\
\text { reporting }\end{array}$ \\
\hline Retrieval Operations & Degassing, mixing, and feed delivery \\
\hline Surveillance & $\begin{array}{l}\text { Operations, radiological controls, and } \\
\text { maintenance surveillances }\end{array}$ \\
\hline Tank Staging & Double-shell tank (DST) inter-tank transfers \\
\hline Waste Sampling & Sampling and characterizing waste \\
\hline Work Control & $\begin{array}{l}\text { Work release, establishing safe boundaries, } \\
\text { radiological controls }\end{array}$ \\
\hline
\end{tabular}


HNF-4553

Revision 0

\subsection{ASSUMPTIONS (AT THE START OF RETRIEVAL OPERATIONS)}

- Single-shell tank (SST) interim stabilization is complete.

- SST retrieval systems installed as part of project upgrades will be controlled local or local-remote by project personnel with support from a qualified operations engineer.

- SST Farms can be turned over to the projects during retrieval upgrades.

- SST Farm critical system parameters can be monitored remotely.

- 241-SY-101 will no longer require periodic mixing operations.

- SY Farm critical system parameters can be monitored remotely.

- Shift operations office will be located in 200 East area.

- Project upgrades are completed to support retrieval operations.

- All planned HANDI 2000 work management modules have been implemented.

\subsection{OPERATIONS AND MAINTENANCE ROLES AND RESPONSIBILITIES}

Shift Operations will be responsible for routine surveillance, routine facility equipment operations, and back-shift facility emergency response.

Retrieval Operations Support will be responsible for operating retrieval systems, staging waste, and delivering feed to Private Contractor. Retrieval operations will be controlled locally by a qualified operations engineer who reports to the Operations Shift Manager.

Facility Operations and Maintenance will be responsible for planning, scheduling and executing facility upgrades, facility preventive and corrective maintenance.

Radiological Control will be responsible for radiological control and routine radcon surveillances

Operations Shift Managers (SOM) will be responsible for setting safe boundary conditions, authorizing changes in facility configuration, facility and site emergency response, and overall facility monitoring, status and reporting. SOM will authorize the start of retrieval activities that require changing facility configuration. SOM will serve as the Tank Farm Building Emergency Director (BED). 


\subsection{STANDARDIZATION OF EQUIPMENT/PROCESSES}

A fundamental tenet of the O\&M Philosophy is that of standardized equipment and processes. Generic design and standardized components allow for consistency of O\&M by reducing the amount of training required for craftsmen and operators, allowing for trend analysis and lessons learned, and reducing the number of spares required to be maintained on hand.

Consideration should be given to standard systems that are easy to maintain, flexible enough to allow for future growth, and robust enough to ensure uninterrupted operations. Once a system architecture design is selected, additional systems should be compatible and, if possible, identical.

\subsection{LESSONS LEARNED}

This document is intended to provide projects with the lessons learned and best practice information for effective incorporation into their project designs. Many of these lessons learned and best practices are based on previous operations, maintenance, and project upgrade activities. If possible, each of the "shall" requirements will be traced to a specific lesson learned document or an O\&M decision document. Where no formal decision documents exist, this document will provide documentation of these requirements.

\subsection{CONTROL OF POTENTIAL RADIOACTIVE AIRBORNE EMISSIONS}

During retrieval operations, it will be necessary to minimize the potential for airborne radioactive emissions from the various activities. To ensure minimal disruption of work activities, a series of "As-Low-As-Reasonably-Achievable Control Technology " (ALARACT) demonstrations have been pre-approved by the Washington State Department of Health and are contained in the Control of Airborne Radioactive Emissions for Frequently performed TWRS Work Activities (ALARACT Demonstrations) (Clark 1999). The radiological controls, monitoring, and records/documentation requirements shall be incorporated into project baselines. More specific requirements are contained in Notices of Construction for the following pits (ER152, 244-A Lift Station, 244-TX, and UX-154) if cover blocks are removed. 
HNF-4553

Revision 0

This page intentionally left blank. 
HNF-4553

Revision 0

\subsection{MONITORING AND CONTROL SYSTEMS}

A monitoring and control system should minimize life-cycle surveillance cost while optimizing system performance and production processes. The O\&M monitoring and control strategy will provide the following:

- Centralize remote surveillance monitoring to reduce life-cycle costs.

- Start up and shut down systems locally to optimize system performance.

- Control retrieval operations local-remotely to optimize production processes.

\subsection{MONITORING}

Only those parameters critical to the operations of the system or component should be monitored. Monitoring should not be performed just for the sake of obtaining data. Each monitored parameter should have a specific operationally related purpose, such as system performance evaluation or trend analysis.

To allow for an integrated processing view and minimize monitoring life-cycle cost, remote monitoring at a central monitoring location is highly desired. The use of remote monitoring will minimize the amount of data recording while touring the facilities. The operators can then be more concerned with identifying abnormalities associated with the operation. Recording data from remote monitoring stations also helps to minimize the amount of time the operators are required to be in radiation areas.

Due to the hostile nature of both the waste and the environment, monitoring and control instrumentation is highly susceptible to failure. From a conduct of operations standpoint, it is unacceptable to operate with failed instruments. If an instrument parameter is important enough to warrant being monitored, the instrument should warrant being fixed if it fails. This can be accomplished by having the instrument located outside of the tank or, for instruments located in the tank, by using redundant instruments.

The SOM's responsibilities for controlling the overall facility operation configuration, requires that they not only have current equipment status (operational, non-operational), but also an integrated view of transfer systems, interconnected tank levels, and supporting leak detection systems. 
HNF-4553

Revision 0

\subsubsection{Remote Central Monitoring Station and System}

1. The Central Monitoring Station and System (CMS) shall provide the remote capability to monitor system and process equipment parameters requiring frequent monitoring, labor intensive data collection, or repetitive entry into contamination and radiation areas.

2. The CMS shall be designed for continuous manning by a single shift operator.

3. The CMS shall serve as both a monitoring station and a central station for authorizing changes in facility configuration in the event of off-normal situations.

4. The CMS shall be centrally located in the 200 East area, adjacent to the DSTs, and outside radiation and contamination areas.

5. The CMS shall have the capability to monitor personnel and vehicle farm access in the event of an abnormal condition with the capability to override the local access controls.

6. The CMS shall provide the capability to transfer remote monitoring capability to a back-up remote station in the event that CMS has to be evacuated.

7. The CMS shall provide voice communication (radio/phone) capability with process facilities and field personnel as required.

8. The CMS shall provide the BED with a command post capability to monitor facility parameters and control emergency personnel in the event of a facility or area emergency.

9. The CMS shall allow for monitoring of critical system parameters, alarm actuation, and provide remote shutdown capability of critical equipment which will allow for remotely placing the facility in a safe condition during abnormal or time-critical situations.

10. The CMS shall provide facility processing and equipment status and the ability to coordinate maintenance outage activities.

11. The CMS shall allow for trending of critical parameters and provide warnings to operators that system parameters are close to exceeding action threshold levels.

12. The CMS shall have the capability to archive and retrieve critical data. 
13. The CMS shall have the capability, with operator action, to remotely disable faulty alarms that could impact critical operation. Date and time the alarm is disabled shall be recorded.

14. The CMS shall provide a simple system interface (single screen) to assist an operator in validating Material Balance Discrepancies (MBD) calculations during waste and feed transfers and flushes. MBD calculations shall be archivable and reproducible.

15. The CMS shall provide a view of the integrated transfer system that includes transfer routing and leak detectors, all interconnected tank levels, critical system status, and process control parameters.

16. The CMS shall integrate all of the new and existing monitoring system using a standard user interface. The CMS operator shall have only one system to operate.

17. Master Pump Shutdown (MPS) shall be integrated into the CMS, enabling a single operator to monitor the MPS system in conjunction with other remote monitoring activities.

\subsubsection{Local and Local-Remote Monitoring}

Local monitoring during start-up ensures that there is an operator in the field to monitor and observe the process and take prompt action in the event of an emergency. Local monitoring also minimizes the possibility of miscommunications while performing a field start-up procedure. Comparing local indications to remote readings, the operator can ensure consistency of the instruments and gain a level of confidence in the remote system.

While local monitoring is desirable for equipment start-up, routine surveillance and process control readings should be monitored remotely. This is true even if regular entries into the farms are required as part of ongoing operations.

1. Local monitoring capability shall be provided to monitor systems and equipment locally. This is required during system start-up and troubleshooting.

2. Monitoring systems shall provide local-remote terminals in each DST farm instrument station for all of the remotely indicated systems and controls related to a particular tank farm.

3. In addition to alarming at the CMS, any condition or situation that presents a safety threat to personnel shall have a local alarm that is both audible and visible to anyone in the area that could be affected by the condition/situation. The conditions that this requirement applies to, but are not limited to, are tank overpressure, hazardous/flammable atmosphere and high radiation levels. 
HNF-4553

Revision 0

\subsection{PROCESS AND SYSTEM CONTROL}

System start-up shall be monitored and controlled locally, allowing the operator to monitor the equipment for expected system response. Following satisfactory system start-up, monitoring and control shall be conducted at a local-remote location for ALARA considerations and for ease of access.

Retrieval operations will only be manned during retrieval evolutions. Operations will be controlled at remote-local stations separate from the Central Monitoring Station.

1. Systems that can be controlled remotely shall provide local monitoring and control capability in the event of remote system failure. This mode of operations will be a back-up due to the increased exposure and manpower requirements.

2. Systems or conditions that pose an immediate threat to personnel shall provide for automatic shutdown, where shutdown will minimize or mitigate the hazards.

3. Systems that can be controlled remotely shall also provide for local manual system shutdowns. 
HNF-4553

Revision 0

\subsection{TRANSFER SYSTEMS}

The double-shell tank (DST) transfer system is critical to both safe storage and retrieval operations. Transfer critical systems should be identified in the master equipment list (MEL) and, in the event of failure, have a contingency plan developed and in place prior to operations. For transfer critical systems redundant back-up systems should be considered. This is especially true for systems that have long recovery delays and high repair costs.

The River Protection Project (RPP) Authorization Basis (AB) interprets an interconnected tank as any tank that has a transfer line physically connected to the transfer route. Physically connected applies to any transfer line that is not separated from the active transfer line by a blank or air space. One or more closed valves does not constitute a separation. All tanks and pits physically connected by the transfer line require surveillances prior to and during the transfer. The use of jumper manifolds in valve pits will cause all of the East Tank Farm's (ETF) DSTs to be physically connected.

During retrieval operations, only 30 days notification will be given to prepare and complete feed delivery. Because of the long lead-time to install flexible jumpers and the short notice involved, valve manifolds are preferred, even though they increase the complexity of conducting a transfer.

To meet the RPP AB requirements for monitoring during a transfer and in the interest of ALARA, the leak detection system and tank liquid level measuring systems will have to be monitored at a central remote monitoring station. Loss of this remote monitoring capability would require operations personnel to locally monitor all of the ETF DST levels and ETF leak detector systems. This type of operation could not be sustained for more than one shift and would be extremely costly and difficult to orchestrate.

During waste transfers, there is a requirement to monitor the transfer route for leaks and to ensure that the waste is not being misrouted. This is accomplished administratively by performing a waste transfer material balance and calculating the Material Balance Discrepancy (MBD) periodically during the transfer. MBD calculations are determined by comparing the combined levels (volume) of the sending and receiving tanks during the transfer to the combined levels of these tanks at the start of the transfer and factoring in any raw water usage. MBD calculations are calculated at intervals specified in the procedure or work package.

To make the MBD as accurate as possible, the tank level indicating devices should be very sensitive. The liquid level detection devices currently being used are "ENRAFs," which are calibrated to $1 / 100^{\text {th }}$ of an inch and have the ability to send a signal to a computer monitoring system. This level of accuracy is important since $2.54 \mathrm{~cm}$ (1 in.) of liquid is equivalent to 10,330 liters (2,750 gal.). 


\subsection{PIPING SYSTEMS}

Prior to starting a transfer, and whenever a transfer is shutdown, the associated transfer line should be flushed with warm to hot water. This will help to pre-heat the line and limit the amount of salts and solids that precipitate out during the transfer. For pre- and post transfer line flushing, the raw water needed should be supplied at the suction of the pump instead of at the discharge. This would eliminate the possibility of having pressurized waste forced into the raw water system and subsequently outside of the pit. It would also eliminate the need for equipment (pressure switches, backflow preventers, relief valves) necessary to protect against this scenario and the maintenance and testing related to this equipment.

In the event a transfer line should plug, the plug will have to be either dissolved or pushed through to the receiving tank. Normally a combination of both processes is used. Initially, high-pressure water is used to start the plug moving or force water around it. Once this happens, the same water is then used to dissolve the plug. After the plug is cleared, the line is then thoroughly flushed to remove any remnants.

To clear a plug, high-pressure water must be applied to the affected transfer line. This pressure is significantly higher than that of the site raw water system.

1. Transfer system rigid jumpers designed for multiple pit wall nozzles (three or more) shall have a flexible piece installed in the jumper. This will allow for ease of installation due to misalignment of either the jumper or any of the wall nozzles. This function can also be accomplished with multi-section jumpers. This also applies to any jumpers with two or more nozzles located $180^{\circ}$ apart since these hard piped jumpers are relatively inflexible.

2. Transfer line encasements shall have a means to drain or be pumped to an approved collection facility if a leak is detected.

3. Transfer line leak detectors shall be capable of detecting a leak in the transfer line encasement and at all mechanical connections associated with the transfer route and physically connected lines (pump pits, valve pits, and diversion boxes).

4. Transfer line leak detectors shall be connected to a MPS and, if activated, will shutdown active transfer pumps and prevent any subsequent restarts until the alarm is cleared.

5. Transfer lines shall be pipe-in-pipe encased with leak detection between the pipes.

6. Transfer line encasements shall be able to contain the entire volume of waste in the failed section of the transfer line.

7. Newly installed or repositioned jumpers shall be leak tested prior to use. 
8. Operations shall independently verify that the planned transfer route is appropriate for the intended transfer and that all piping is in place, per configuration controls, prior to the start of a transfer.

9. Inactive nozzles on physically connected jumpers/piping systems shall be sealed with caps, process blanks, or equivalent to prevent the misrouting of waste.

10. Transfer lines, valve pits, and diversion boxes made obsolete by project upgrades or retirement shall be physically isolated to minimize transfer preparations time, required function checks, and transfer shutdowns due to spurious and unrelated alarms.

11. Even though pits provide a containment function, equipment designs that provide a high probability of releasing tank waste into the pit shall be avoided. This includes pump seals, rupture disks and relief valves. This will eliminate the buildup of contaminated waste and the associated radiation levels, minimizing the impacts to future operations and maintenance activities.

12. Transfer line leak detectors that connect or drain to the dome space or ex-tank region of a waste tank, receiver tank, or catch tank must have the appropriate flammability/explosive rating for that environment.

13. All waste feed deliveries to the Private Contractor (PC) shall be followed by a flush containing corrosion inhibited water.

14. Where the capability exists, internal tank to tank waste transfers shall be followed by a flush containing inhibited water.

15. The use of transfer system quick disconnect fittings that extend outside of a pit shall be minimized. If required, they should be located inside the pit with easy accessibility through a removable cover.

16. Transfer lines shall provide a connection point for high pressure flush water that is designed for use to clear plugged lines. Connection should allow controlled venting prior to opening.

\subsection{VALVING SYSTEM}

The establishment of a transfer route relies on the use of manual valves in areas such as encasement drain valves, raw water lines, physically connected piping configurations, etc. These systems/valves are not able to be readily modified to accommodate computer control systems. Because of the presence of these manual valves, the total control of transfer routes by a computer system and Motor Operated Valves (MOVs) is not feasible for the Waste Feed Delivery (WFD) Phase 1 (Kison 1999). 
Transfer line and encasement drain valve positions will be verified prior to the start of a transfer. Operations will independently verify that the planned transfer route valving is aligned correctly prior to transfer. Normally, transfer line valve line-ups are controlled procedurally and the valves operated manually. Since Operators are required to make multiple entries into the tank farms to complete the $\mathrm{AB}$ transfer preparation requirements and the transfer system valve set-up is rarely the critical path during transfer preparations, unless the entire transfer system is controlled by remotely operated valves, there will be no appreciable reduction in transfer preparation time or operator exposure by installing transfer system MOV's. Due to the expected long duration of WFD transfers ( 1 to 5 days), and the infrequency at which transfer routes will be realigned (approximately 3 per month), the benefits of computer controlled remotely operated valves are out-weighed by the cost and time associated with periodic maintenance and repairs to these valves.

Remotely operated transfer system valves should only be considered where there is a requirement to do any of the following:

- Continually reposition the valve for process control;

- Reposition the valve quickly (less than 30 minutes) to mitigate a hazard; or

- Repositioning the valve manually requires routine personnel entry into a high radiation area and unacceptable personnel dose rate.

Remote electronic valve position indication is desired to prevent a transfer misroute, by providing operations personnel with a near real time integrated transfer system configuration and status view. Electronic Valve Position Indicators (VPIs) connected to CMS provides Operations with increased confidence in the waste going where it is supposed to go, and added "defense in depth" for transfer system configuration management. The disadvantages of valve position indicators are the associated increased maintenance requirements and the functional tests that will be necessary if they are to be relied upon to perform a safety function.

1. VPIs shall shutdown, or prevent the starting of, the transfer pump via the MPS in the event that the valve is in the incorrect transfer configuration or repositioned during the transfer. This only applies to those transfer valves on the active transfer route.

2. VPIs and valve motor-operated or gear-operated drives shall be located atop or above the cover blocks of the valve pit to allow repair and preventive maintenance activities of the equipment without a pit entry.

3. VPI cables and wires shall be designed so that they don't present a safety hazard to personnel working in, on, or around the pit.

4. VPI cable and wires that have to be disconnected for maintenance or pit cover removal shall be designed so that they cannot be reconnected incorrectly after the maintenance is completed

5. Valve reach rods shall be designed to be removed easily and, when reinstalled, only engage the valve in the correct alignment. 


\subsection{PUMPING SYSTEM}

If a transfer pump seal is located in the pump pit and the seal or support system fails, contamination would be spread to the pump pit and the waste would cause the leak detector to alarm, shutting down the transfer pump. The increased radiation and contamination levels would further complicate replacement of the failed seal. By locating the seal in the tank, if it should fail, the waste would be contained without further spread of contamination and the transfer could continue at reduced capacity. Pump seals should be of the mechanical variety currently in use and should be located inside the waste tank. When using a pressurized pump seal system, there is the possibility that waste could be forced into the gas seal system if its pressure dropped below waste pressure in the seal.

Transfer pump motors should be located above the pit cover if feasible to facilitate routine and corrective maintenance and to help prevent overheating.

1. Transfer pump systems and components shall be of a generic design and should be standardized as much as possible.

2. Transfer pumps shall have the capability to be locked out with an administrative lock.

3. Transfer pump process control instruments installed in pits shall be limited to those critical for safe operations. If required, installed back-ups should be considered.

4. Transfer pump system wires and cables that have to be disconnected for maintenance or pit cover removal shall be designed so that they cannot be reconnected incorrectly after the system is restored. If this is not feasible, verification will be controlled by in-process inspection.

5. Transfer pump seals that require an external pressure source located in the pump pit shall be avoided.

6. Transfer pumps shall have an interior and exterior surface that can be thoroughly flushed and cleaned. Surfaces should be as smooth as possible and there should be a minimum of waste trapping locations (elbows, recesses, brackets, etc.) on the exterior. If the equipment is designed to have waste contact the interior, the interior must be able to be flushed.

7. Transfer pumps shall be self-venting and self-priming

8. Transfer pumps with flexible hoses shall be designed with a capability for venting the pump and discharge piping in the event the suction hose kinks and the pump becomes air-bound. 


\section{HNF-4553}

Revision 0

9. Transfer pump run-in capability shall be provided.

10. Spare transfer pump long-term vertical storage capability shall be provided. 
HNF-4553

Revision 0

\subsection{WASTE PREPARATION SYSTEMS}

Due to the extremely hostile nature of the tank environment, waste preparation systems should be installed "just in time" to minimize the time prior to start-up that the equipment is exposed to the tank environment. This will prevent damage caused by radiation and caustic atmospheres and prevent areas with close tolerances from binding due to waste build-up. If waste preparation systems must be installed early, a program to exercise the moving parts and prevent binding shall be implemented. This could be done manually or by "bumping" the motors periodically

\subsection{MIXER PUMP SYSTEMS}

Normally, the relatively minor waste motion experienced during a transfer has little effect on the installed equipment in the tanks (ENRAFs, thermocouples, etc.). However, if it is intended to transfer waste while mixing the tank contents, the effect on this equipment should be evaluated.

A permanent camera system installed in a tank requires a substantial amount of support equipment as well as maintenance and testing. This is a substantial expense for a system that would be used only periodically. Considering the relatively small number of transfers and mixing operations that will be occurring at one time, portable video systems could be used at a lower cost and with much less maintenance. Additionally, portable video systems can be installed and operated through 4-in. risers. A permanent camera system would have to be installed through a riser larger than 12 in., of which there are very few per tank.

1. Mixer pump systems and components shall be of a generic design and shall be standardized as much as possible.

2. Mixer pumps installed in the sludge/waste should have water-lancing capabilities integrated into the design. This would help to minimize the amount of waste generated during installation and provide a means to deliver dilution water to the suction of the pump.

3. Mixer pumps shall have an interior and exterior surface that can be thoroughly flushed and cleaned. Surfaces should be as smooth as possible and there should be a minimum of waste trapping locations (elbows, recesses, brackets, etc.) on the exterior. If the equipment is designed to have waste contact the interior, the interior must be able to be flushed.

4. During simultaneous mixing and transfer operations, the tank level measuring device may not be reliable for accurate MBD calculations, and an alternative capability for accounting for tank inventory during transfers may be required (e.g. transfer system flow indication). 
HNF-4553

Revision 0

5. Mixer pump run-in capability shall be provided.

6. Spare mixer pump long-term vertical storage capability shall be provided.

7. Installation of permanently installed in-tank cameras shall be avoided.

8. A method to flush the pump internals with water regularly to keep salts dissolved, shall be provided.

\subsection{DILUENT AND FLUSH SYSTEMS}

The proposed diluent and flush systems will support multiple retrieval projects in multiple tank farms. Because of this the diluent and flush system provides a potential single point failure for multiple retrieval projects, possibly effecting both primary and contingent feed tanks. The loss of this system could shutdown retrieval operations in several tank farms until restored.

For the diluent and flush heating system, electric heating is preferred, allowing for increased flexibility of operations and ease of maintenance.

1. The diluent and flush system shall be designed with redundant system capability for reliability and to allow repairs and maintenance without interrupting operations.

2. The diluent and flush system shall have a means of measuring flow rate and total volume flushed to support MBD calculations during transfer.

3. The diluent and flush system shall be provided with two manual valves to isolate the system from the transfer system when not in use.

4. The diluent and flush system isolation valves shall have the capability to be locked out.

5. The diluent and flush system shall be provided with a bypass capability to allow transfer system flushes from another source in the event of multiple diluent and flush system failures.

6. The diluent and flush system shall be provided with a means to control caustic delivery system pressure from source to receiving tank.

7. The diluent and flush caustic delivery system shall be designed so that temporary containment is not required for system operation. 


\section{HNF-4553}

Revision 0

8. The diluent and flush caustic delivery system piping shall have an appropriate (polyethylene or similar) sleeving built into the design from the caustic source to the receiving tank. Operations should not have to provide this protective sleeving. 
HNF-4553

Revision 0

This page intentionally left blank 


\subsection{STORAGE SYSTEMS}

Access to the tank dome space or waste is through risers. These risers may be located in pits on top of the tank or by themselves protruding through the soil cover. There are several different sizes of risers and numerous different uses for risers. Some risers have permanently installed equipment in them while others are available for access to the tank.

Due to tank construction and welding processes as well as activities in and around the tanks over the years, many risers are neither round nor straight. When designing equipment to be installed in a riser, tolerances should not be so tight that an out of round or bent riser will preclude its installation. An item to be installed in a 12-in. riser should have a diameter no larger than 11 in. This way, if the riser is not round or there is a minor obstruction (e.g., weld bead), the component will still fit. If the component cannot be designed with this much contingency, the riser it is to be installed in should be tested with a go/no-go gage. Not all risers are available for retrieval operations. Some risers are reserved for future installation of equipment while others are being maintained to provide access for sampling.

Any work in a pump or valve pit is considered either ex-tank or dome space intrusive and requires specific controls as identified in the RPP AB, Administrative Control's 5.9, 5.10, and 5.11. Activities in a pit that have the potential for generating a spark are also per the RPP AB. This includes the use of grounded/bonded tools and equipment and using spark-free tools. The atmosphere must be considered flammable/explosive until it is verified otherwise. Flammable environment verification may be performed using portable methods (manually monitored by Industrial Hygiene Technicians using approved instruments) or permanently installed methods (Flammable Gas Monitors (FGMs) and Standard Hydrogen Monitoring System (SHMS) cabinets). Work that is performed in the waste or the dome space of a tank must also have these controls. Depending on what Facility Group the tank is in, these controls may be relaxed once the atmosphere is determined to be below limits.

\subsection{CONFINEMENT SYSTEM}

When installing long-length equipment into tanks, care should be taken to ensure that it would not penetrate the bottom of the tank if dropped. This can be accomplished through the use of impact limiters or any other means that prevents the item from reaching the bottom of the tank if dropped. Equipment that is to be installed into the waste will need to have the waste penetrated first. This is normally accomplished by using a separate lance and high-pressure water.

While the pit cover blocks do not provide an airtight seal, they do significantly restrict air flow between the tank atmosphere and the outside atmosphere. This minimal atmosphere exchange allows the pit covers to provide a radioactive contamination containment function. For this reason, atmospheric and radioactive conditions must be verified prior to removing pit cover blocks. 
1. Radioactive containment (glove bags, catch basins, sleeves, etc.) used around an open riser shall meet the controls of AC 5.10 of the RPP AB. Any tools and equipment used must also meet these controls.

2. Any system or component that contains tank waste shall not extend outside of a pit unless an alternate means of containment is provided.

3. When accessing the tank dome space or waste through a sealed riser, non-sparking tools and equipment shall be used until the atmosphere is determined to be nonflammable and the flammability category for that tank allows for the relaxation of these controls.

\subsection{INSTRUMENTATION AND CONTROL SYSTEMS}

Instrumentation installed in Tank Farm systems will be exposed to high levels of radiation, caustic chemicals, extreme temperature ranges, and a wide range of elements and conditions not normally presented to most instrumentation. These instruments should be standardized, rugged, and have a history of proven performance with minimal maintenance.

Whenever possible, instruments that can be operated throughout the design life of the system or component without any calibration or maintenance should be the first preference, with the order of preference reduced based on the amount of maintenance required, avoiding those instruments requiring frequent calibration or testing.

Instrumentation should be designed so that it can be tested and calibrated from outside of the tank or pit. If this would require sensing lines that come in direct contact with pressurized tank waste that could provide an unconfined path to the environment during normal operation, this will not be possible and a pit entry will be required. Some instruments can be removed from a pit and either repaired or replaced. However, this is extremely expensive and time consuming and should be minimized as much as possible.

An instrument required for all transfers, such as a flow meter, that can be installed in a location that serves all of the transfers should be the preferred alternative to installing one on every tank. This minimizes the number of instruments that can fail and the amount of maintenance and testing that is required for that type of instrument. This also provides for a more cost effective method of maintaining the required number of spare parts on hand. This does, however, increase the possibility of a system-wide shutdown if it should fail. For this reason redundant instruments should be considered.

Any instrument designed to perform a safety function will require periodic calibration and functional testing while its associated system is considered operational.

Instrumentation cabinets should not be located near pits requiring cranes for access to avoid damaging the cabinets during crane operations. 
1. Any instrument installed in a tank, both in the waste and in the dome space, or in a pump or valve pit, must meet the flammability requirements for those spaces as specified in the RPP AB.

2. Recovery plans shall be generated and put in place for any instrument that is determined to be critical to continued operations.

3. Programmable Logic Controllers (PLCs) shall be standardized (e.g. 4-20 mil-amperes output) so that their output signal can be easily integrated into a single monitoring and control architecture.

4. A contingency for obtaining the liquid level in interconnected tanks shall be in place to prevent or minimize transfer shutdowns in the event of a primary liquid level measuring device failure.

5. Instrument enclosures that require internal access during routine operations and maintenance shall have exposed wires and terminals covered/protected to prevent electrical shock hazards to personnel.

6. If feasible, instrumentation shall be located outside radiation areas to facilitate maintenance and should be located in the instrument control room to protect it from harsh environmental conditions.

7. Instrumentation wires shall not be installed overhead so as to interfere with crane operations. 
HNF-4553

Revision 0

This page intentionally left blank. 
HNF-4553

Revision 0

\subsection{UTILITY SYSTEMS}

Systems that extend outside of a pit (e.g. raw water, or nitrogen seal) and have the potential to be exposed to pressurized tank waste must have a means of preventing the system from being contaminated with tank waste. This normally consists of pressure switches or valve position limit switches that prevent the transfer pump from operating.

\subsection{ELECTRICAL}

Any electrical equipment installed in a valve or pump pit must meet the flammability and explosion classifications described in the RPP AB. This applies to pump motors, pressure switches, flow meters, leak detectors, position indicators, heaters, and any other equipment that has the potential for generating a spark.

\subsection{INSTRUMENT/SERVICE AIR}

Because of the decreasing dependence on instrument and service air systems, new systems should be designed to be simple and easily maintainable. Many of the current instrument and service air systems are being operated at such a low capacity that they can be replaced by low capacity, inexpensive, off-the-shelf systems. Because of some of the critical systems that instrument air supports, redundant instrument air systems with alternate power sources should be considered.

1. Air systems shall be fitted with quick disconnects allowing for ease of air compressor replacement and connecting of temporary air sources.

\subsection{SERVICE (RAW) WATER}

In order to clear a transfer line plug, high-pressure water may have to be applied to the affected transfer line. This will require an external pressure source that is significantly higher than that of the site raw water system. There would be no benefit to having the raw water system connected to the discharge of the pump to perform this function. During normal operations, pump and transfer line flushes could be performed using the water already being supplied at the suction of the pump. If the line plugs, the discharge jumper will most likely require removal to facilitate connecting an external pressure source.

Service water usage or tank levels will be monitored every 24 hours. Monitoring service water usage requires reading each tank farm's flow-totalizer to verify that there has been no unaccounted for service water usage. Monitoring tank levels requires a verification that the waste levels in tank farms serviced by the water system are not increasing. 
HNF-4553

Revision 0

1. Service water flow to each DST farm shall be monitored by flow-totalizers. This parameter should be monitored remotely at the central monitoring station.

2. A pressure switch, with interlock, to the waste transfer pump shall be installed between the service water system and the waste transfer piping. Where automatic interlock is not available, the isolation of the service water line by two closed valves and a pressure switch with an alarm that actuates/signals in a continuously monitored area is acceptable. 


\subsection{MAINTENANCE AND RECOVERY SYSTEMS}

\subsection{WORK CONTROL}

The SOM will release and monitor facility maintenance activities using the HANDI 2000 Work management system. This will be done after safe condition boundaries have been established. Work will be reviewed, authorized, released, and statused on-line, eliminating the need to co-locate the shift manager with planning and maintenance personnel.

1. Shift operations office shall be located separate from the CMS to avoid distracting the operator, but located close enough (in the same building) to allow for easy access by the SOM for monitoring functions.

2. A HANDI 2000 Work management station shall be available at CMS and in the shift office, so that the CMS operator and SOM can quickly gain access to the status of ongoing work.

\subsection{WORK SCHEDULING}

Maintenance will be scheduled around farm and system outages that best support retrieval operations. A maintenance outage refers to a period of time that all of the equipment in that farm is available for maintenance, including electrical distribution systems, without impacting the WFD schedule. All scheduled work will be put on the work schedule one day prior to release to allow for proper pre-work planning. Maintenance for the day will be released the night before by the SOM via the HANDI 2000 Work management system. Maintenance personnel will report work status on-line.

To support required functional tests and calibrations for transfers, as many leak detectors as possible should be grouped together and tested at the same time. This will minimize the number of times the transfer has to be shut down. This may require moving the performance date of some leak detectors forward, but should not be used to extend any beyond their due dates.

1. In the event of an unplanned outage, the maintenance department shall maintain a backlog of work that can be completed during that outage without impacting the restart of the farm when the situation that caused the outage is corrected.

\subsection{INVENTORY/SPARE PARTS}

It is understood that certain high cost, one-of-a-kind replacement items cannot be maintained in ready spares due to the inability to predict which ones will fail and the exorbitant cost of procuring one of each item. For this situation, these types of items should be identified 
and a contingency plan put in place in the event of a failure. An example of this type of item is a jumper for a specific pump or valve pit. A contingency measure would be to have one or two backup tanks identified, characterized, qualified and ready to be transferred in the event this type of equipment should fail.

Tank farm warehouses should be integrated into the HANDI 2000 Inventory module. This will provide planning personnel with an accurate spare-parts inventory and current material procurement status.

1. Projects shall complete a bill of material, using the master catalog of facility qualified parts, for new and upgraded systems and components prior to turnover.

2. A pre-approved bill of materials (parts list) shall be in place for all critical retrieval components.

3. Engineering and Quality Assurance shall control the qualification of parts from within the Master Catalog. Parts to be ordered for specific equipment locations are qualified to that facility in the HANDI 2000 inventory module.

4. For those parts that are not facility qualified, Projects shall work with Engineering, Quality Assurance, and Inventory personnel to help in identifying new master catalog specifications and requirements needed to add facility qualified parts to the HANDI 2000 master catalog.

5. Whenever new equipment is being considered, the amount and frequency of preventive maintenance must also be considered. When there is a choice between similar types of equipment, the one requiring the least amount of maintenance shall be considered first.

6. Depending on the predicted failure rate, enough replacement parts shall be on hand so that system restart is not dependent upon the delivery date of the vendor.

7. In order to minimize one-of-a-kind procurement scenarios, systems and components shall be of a generic design and be standardized as much as possible.

\subsection{PIT WORK (VALVE PITS /PUMP PITS/DIVERSION BOXES)}

Pit work is some of the most costly, time consuming, and high hazard work done in the tank farms. Pit work often requires cranes and crane crews, building containment tents, working in high contamination and high radiation fields, and wearing restrictive personal protection equipment. Only components that serve a direct mission-related process requirement should be installed in pits.

Almost all pit work will involve the use of mobile cranes, if just to remove the cover blocks in order to gain access. Tank dome loading issues will have to be considered whenever 
mobile cranes are used in the tank farms. For some pits, the cover blocks weigh enough that only the largest mobile cranes will be able to lift them. This could present a significant domeloading problem for some of the tanks. One way to avoid this would be to build cover blocks in smaller sections. This would allow the use of smaller cranes and still provide the required containment function. If the cover blocks cannot be built smaller and the larger cranes are required, new equipment installations must not obstruct access to the pit. The heavier the cover block, the closer the crane will have to get to the pit.

Prior to removing cover blocks, all interference must first be removed. Interference can consist of valve reach rods, actuators and motors, temporary leak detectors, portable video equipment, temporary scaffolding, and wire/cables for position indicators and motor operators. Once interference is removed, radiological and industrial safety controls must be put in place. When a cover block is removed, it has to be surveyed and set aside until it is ready to be reinstalled. This may involve wrapping it in plastic to contain removable contamination.

Radiological controls for pit work can consist of simple drapes made of plastic sheets to multi-room containment tents with removable ceilings and portable exhaust systems. The type of containment is dependent upon the radiological conditions that currently exist and past history of work in that particular pit.

Pit work is extremely dependent on favorable weather conditions. Weather will have a significant effect on the required radiological controls and must be considered during the planning and execution of pit work. Depending on the type of containment, wind and rain conditions on the planned work execution day will be a large contributor in determining whether a job can work or have to be rescheduled.

It is very rare to send a person into a pit to perform work. Normally, radiation levels and contamination levels preclude personnel access. Beside the high radiological hazards, valve pits and diversion boxes are classified confined spaces.

Before opening a pit, operations is required to lock and tag any systems that could possibly transfer radioactive waste through any transfer line in the pit to be entered. Pit lock and tag can be as simple as one tag on one pump or as complicated as going to a process facility and over-tagging their equipment. This can be a time consuming activity that can take several days.

1. Equipment designs that require personnel to enter a pit for installation or maintenance shall be avoided.

2. Components shall be specified for simplicity, robustness, and be of proven design and manufacture.

3. Components installed in contaminated pits that require direct maintenance or testing shall be avoided.

4. All work necessary to install jumpers and equipment in a contaminated pit shall be able to be accomplished from outside of the pit. 
HNF-4553

Revision 0

5. Equipment installed in pits shall have lifting bales positioned so that it hangs from the crane in the position required for installation.

6. There shall be no requirement for special one-of-a-kind tools or equipment to complete installation of equipment in a contaminated pit. 


\subsection{EQUIPMENT CONFIGURATION CONTROL}

\subsection{MASTER EQUIPMENT LIST}

The RPP master equipment list (MEL) shall be placed in the control of the HANDI 2000 Work management module database. This system will allow for a seamless information turnover of system and equipment upgrades from the control of the projects to the custody of operations and maintenance. Equipment identification and documentation, preventive maintenance procedures, operating procedures, approved parts list, inventory stores, as-built drawings, equipment history, contingency plans, and model work orders are types of information to be turned over to operations and maintenance. This information may be transferred as a single integrated package to the RPP MEL.

1. Projects shall start placing equipment information in the RPP MEL once a conceptual design is determined and ensure the status of the equipment is "Design".

2. Projects shall update the RPP MEL as the project progresses. An important part of project turnover is to ensure the MEL information is reclassified from a "Design" status and placed in an "Active" status.

3. Projects will update the RPP MEL for all equipment upgrades to include or identify safety equipment classification, instrument set points \& corresponding ranges, and related drawing \& vendor information.

4. Projects shall include equipment component maintenance requirements with requisite procedures and data sheets to fulfill those requirements.

5. Projects shall include documented justification for all equipment components that will not be periodically maintained.

6. Material history shall be retained for all critical retrieval systems within the RPP MEL.

7. Safety equipment shall be identified and the Safety Equipment List (SEL) updated.

8. Instrument set points and corresponding ranges shall include engineering documentation justification. 
HNF-4553

Revision 0

\subsection{DRAWING AND LABELING}

The drawing and labeling functions shall be conducted in accordance with the procedural requirements specified in TWRS Administration Manual (PHMC 1999a). Drawing controls for preparation, accuracy, release and as-built criteria are specified in this manual to ensure the consistency of technical information as well as provide for an orderly transfer of this information in accordance with established turnover requirements.

Identification of equipment (labeling) is performed to a standardized numbering scheme supporting human factors, including the necessary labeling features and placement criteria that supports the safe and efficient operation and maintenance of tank farms. 
HNF-4553

Revision 0

\subsection{WASTE SAMPLING SYSTEMS (TBD)}

\subsection{MISCELLANEOUS SUPPORT SYSTEMS}

\subsection{PERSONNEL/VEHICLE ACCESS CONTROL}

Personnel and vehicle entry into Resource Conservation and Recovery Act of 1976 (RCRA) controlled areas (DSTs) shall be controlled locally with a secure system that validates personnel training and Radiation Work Permit (RWP) requirements, and records and monitors personnel and vehicle access/egress.

This system should have the ability to deny/control access to specific farms in the event of an abnormal or emergency situation. The Building Emergency Director (BED) and the Incident Commander (IC) should have the ability to activate this feature from the Shift Office and the CMS. The BED and the IC should also have the ability to override this feature to allow emergency response personnel to enter the affected farm.

1. Vehicle access within the tank farm boundaries shall meet the RPP AB AC 5.10.2, "Vehicle Controls" requirements.

\subsection{SHIELDING}

Since the farms are not designed for continuous occupancy, shielding requirements for new systems and components should be limited to that necessary to prevent general radiation levels from increasing.

It is not necessary to design shielding to reduce radiation levels below that for a continuously occupied space since the radiation levels in the farm are already well above the continuous occupancy levels. These levels would not be measurable due to the existing background levels, with the cost and weight of the additional shielding presenting a greater obstacle to maintenance and operations.

If increased shielding is deemed necessary, the benefits should outweigh the cost in money, downtime and exposure when maintenance, modifications and repairs are necessary.

When designing shielding, the total exposure should be considered, not just the exposure received during one aspect of the operation. Changes to shielding should also consider dome loading requirements. 


\subsection{LIQUID OBSERVATION WELLS IN SINGLE SHELL TANKS}

Some risers that access the dome space have metal or fiberglass pipes with sealed bottoms called Liquid Observation Wells (LOWs). LOWs are installed in SSTs and extend to just above the bottom of the tank. They are used to monitor liquid levels in tanks that don't have a liquid surface by monitoring the interstitial liquid level of the salt cake. Removing an expandable plug normally accesses these risers/LOWs in lieu of bolted flanges.

LOWs are relatively fragile. Tank waste rollovers have been known to bend them and shear them off. Equipment installed to mix the waste (suspend solids) or dissolve the salt cake may very well damage the LOWs. This must be considered when selecting a method to perform this function. Any activity that will cause the waste to move around the tank significantly will probably require the LOWs to be removed first. Since liquid will most likely be added to dissolve salt cakes, standard level detection devices should be able to be used and the LOWs removed.

\subsection{LONG LENGTH EQUIPMENT LAY-DOWN AREA}

Retrieval operations will require removing and installing numerous internal tank longlength equipment systems. An approved equipment lay-down area should be constructed close to the DST to allow for temporary storage of this equipment and associated containment containers. 
HNF-4553

Revision 0

\subsection{REFERENCES}

Clark, D. E., 1999, Control of Airborne Radioactive Emissions for Frequently Performed TWRS Work Activities (ALARACT Demonstrations), HNF-4327, Rev. 0, Lockheed Martin Hanford Corporation, Richland, Washington.

Jones, G. L., 1999, Tank Waste Remediation System Technical Safety Requirements, HNF-SD-WM-TSR-006, Rev. 0S, Fluor Daniel Hanford, Inc., Richland, Washington.

Kison, P. F., 1999, Alternatives Generation and Analysis for Valve and Control Systems For Phase I Privatization, HNF-4521, Rev. 0, Lockheed Martin Hanford Corporation, Richland, Washington.

PHMC, 1999a, TWRS Administration Manual, HNF-IP-0842, Volume II, Section 6.1, "Tank Farm Operations Equipment Labeling," Fluor Daniel Hanford, Inc., Richland, Washington.

PHMC, 1999b, TWRS Administration Manual, HNF-IP-0842, Volume II, Section 3.5, "Engineering Documents," Fluor Daniel Hanford, Inc., Richland, Washington.

Resource Conservation and Recovery Act of 1976, 42 USC 3901 et seq. 
HNF-4553

Revision 0

This page intentionally left blank. 


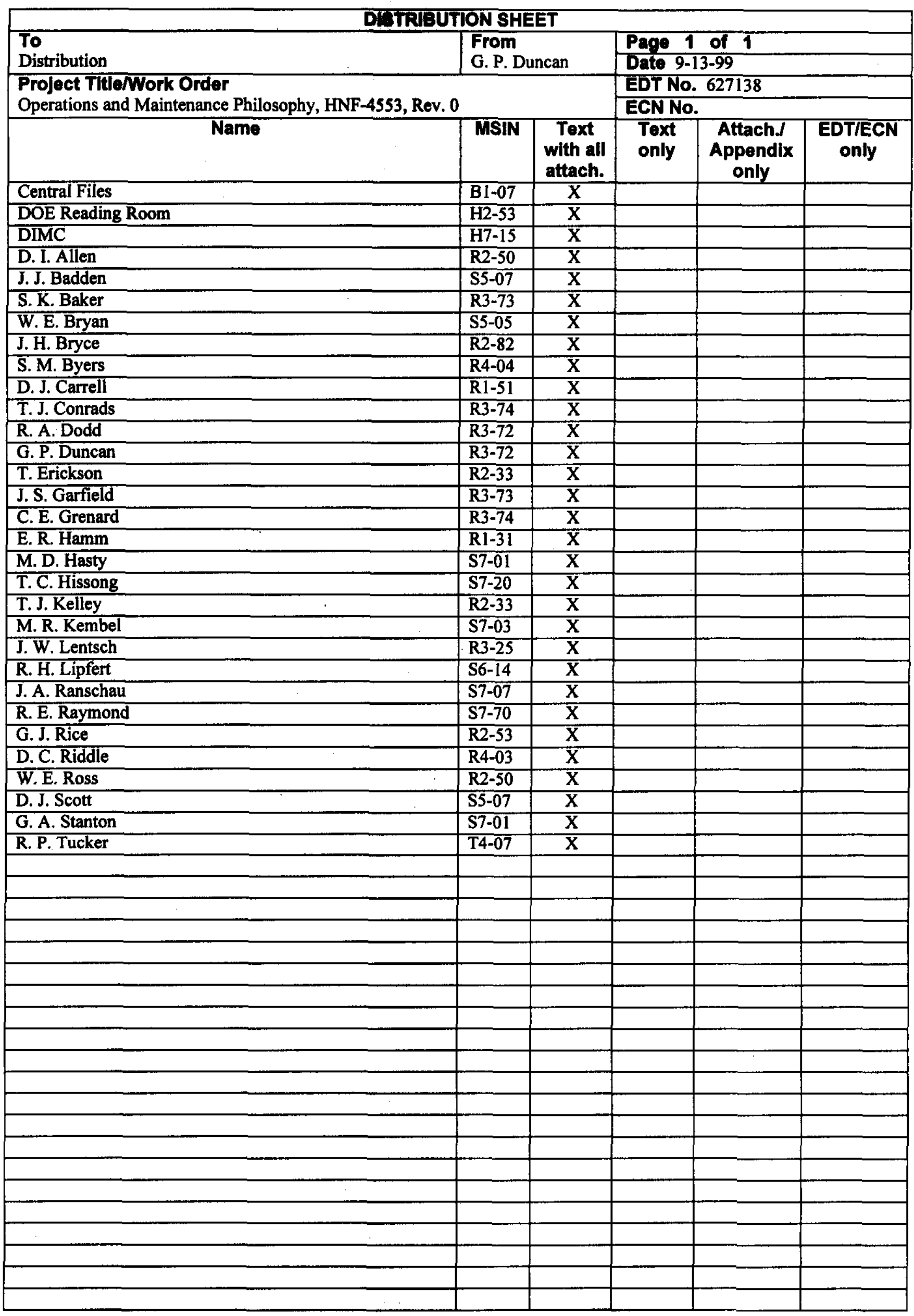

